with local disease parameters (lymphocytic focus score (LFS); $\mathrm{r}=0.744$ and $\% \operatorname{Ig} \mathrm{A}^{+}$cells $\left.\mathrm{r}=-0.658\right)$ as well as with immune cells present in the LSG (CD3 $r=0.890$; CD20 $r=0.717$; CD1a $\mathrm{r}=0.660$; CD208 r=0.763).

FACS analysis of isolated cells from patients' LSG confirmed a strongly increased percentage of both CD3 and IL-7 R+ CD3 $\mathrm{T}$ cells in pSS as compared to nSS (both $\mathrm{p}<0.01$ ). Furthermore, abundant IL-7R expression was detected on high proportions of CD 4 and CD 8 (on average $66 \% \pm 5 \%$ and $56 \% \pm 4 \%$, respectively). Other CD45 $5^{+}$leucocytes and $\mathrm{CD} 45^{-}$tissue cells did not or hardly express the IL-7R. IL-7R+ CD3, CD4 and CD8 $T$ cells as percentage of the total LSG cells significantly correlated with the LFS ( $p \leq 0.05, r=0.533 ; p \leq 0.01, r=0.593 ; p \leq 0.01$, $\mathrm{r}=0.631$, respectively).

The abundant presence of IL-7R $\mathrm{R}^{+} \mathrm{T}$ cells in the inflamed salivary glands of pSS patients, which correlates to inflammation, suggests that increased IL-7 expression could significantly contribute to glandular inflammation by activation of IL-7 $\mathrm{R}^{+}$ effector T cells. Hence, blockade of the IL-7R might be a novel therapeutic strategy for pSS.

\section{A119 IL-7 RECEPTOR EFFECTOR T CELLS ARE INCREASED IN THE INFLAMED SALIVARY GLANDS OF PSS PATIENTS AND CORRELATE WITH INFLAMMATORY MARKERS}

A Bikker, ${ }^{1}$ AA Kruize, ${ }^{1}$ M Wenting, ${ }^{1}$ M Versnel, ${ }^{2}$ JWJ Bijlsma, ${ }^{1}$ FPJG Lafeber, ${ }^{1}$ JAG van Roon' 1 Department of Rheumatology and Clinical Immunology, UMC Utrecht, Utrecht, The Netherlands; ${ }^{2}$ Department of Immunology, Erasmus MC Rotterdam, Rotterdam, The Netherlands

\subsection{6/ard.2010.148981.22}

In patients with pSS local T cell-driven inflammation contributes to destruction of exocrine glands associated with clinical symptoms of dryness. Recently the authors documented increased interleukin (IL)-7 in labial salivary glands (LSG) of pSS patients that was capable to induce Th1 and Th17 activity and proinflammatory cytokine secretion. IL-7 mediates its effects by signaling through the high affinity IL-7R $\alpha$ subunit and $\gamma c$ chain. The authors and others have shown that IL-7R+ CD4 T cells that strongly proliferate upon TCR activation, while IL-7 ${ }^{-}$CD4 $\mathrm{T}$ cells are anergic and can be regulatory of nature. This suggests that IL-7 $R^{+} T$ cells contribute to the increased inflammatory response in LSG of pSS patients, especially in the presence of increased local IL-7 expression.

To identify IL-7R expression in the labial salivary gland and to examine the phenotypical characteristics of $\mathrm{IL}_{-}-7 \mathrm{R}^{+} \mathrm{T}$ cells between pSS and non-Sjögren's syndrome sicca (nSS) patients. The presence of infiltrating immune cells and IL-7 $\mathrm{R}^{+}$ cells in inflamed salivary glands of pSS patients $(n=14)$ and non-inflamed LSG of nSS patients ( $n=7$ ) was studied by immunohistochemistry and FACS analysis upon tissue digestion.

In the LSG of pSS patients significantly increased numbers of IL-7 $\mathrm{R}^{+}$cells were found as compared to nSS (pSS vs nSS; $244.3 \pm 40.7$ vs $12.3 \pm 4.6$ cells $/ \mathrm{mm}^{2}$ ). IL7R $\mathrm{R}^{+} \mathrm{T}$ cells were found throughout the tissue but mainly in the CD3-rich lymphocytic areas. IL7R $\mathrm{R}^{+} \mathrm{T}$ cells significantly (all $\left.\mathrm{p}<0.01\right)$ correlated 